\title{
Thermal imaging evaluation of paravertebral block for mastectomy in high risk patient: case report
}

\author{
Marcin Możański • Bartosz Rustecki • \\ Bolesław Kalicki · Anna Jung
}

Received: 18 March 2014/ Accepted: 15 July 2014/Published online: 25 July 2014

(c) The Author(s) 2014. This article is published with open access at Springerlink.com

\begin{abstract}
Thoracic paravertebral block is the technique of injecting local anesthetic adjacent to the thoracic vertebra close to where the spinal nerves emerge from the intervertebral foramina. It is effective in treating acute and chronic pain of unilateral origin from the chest and abdomen. This technique causes pain relief with pulmonary function preservation and great hemodynamic stability. 66 year old woman $(156 \mathrm{~cm}, 80 \mathrm{~kg}$, BMI 32) with chronic right heart failure, hypertension and obesity, on chronic oxygen therapy was presented for elective mastectomy due to breast cancer. She suffered from severe COPD and also bullous emphysema. FVC 1.59 1; FEV1 0.551 ; FEV1\%FVC 34.6. The paravertebral block was performed using the multi-shot percutaneous technique with additional light general anesthesia. For confirmation, of proper analgesia range, control of temperature changes, using FLIR i7 infrared camera, was performed. Control photos were made $20 \mathrm{~min}$ after the blockade and then $10 \mathrm{~min}$ later. Infrared photo showed rise of temperature reading in every marked region. There were no hemodynamic and pulmonary complications postoperatively. Paravertebral block in combination with sedation creates excellent conditions for breast surgery procedures. Additional temperature changes monitoring performed with infrared camera may confirm proper range of analgesia needed to perform surgery. Great cardiovascular stability and very good pulmonary function preservation make this method excellent
\end{abstract}

M. Możański · B. Rustecki ( $₫)$

Department of Anesthesiology and Intensive Care, Military

Institute of Medicine, St. Szaserów 128, Warsaw, Poland

e-mail: bartrust80@onet.pl

B. Kalicki · A. Jung

Department of Pediatrics, Nephrology and Allergology, Military

Institute of Medicine, St. Szaserów 128, Warsaw, Poland for high risk patients. Low complication rate is additional advantage. In our opinion this method is recommendable.

Keywords Paravertebral block · Mastectomy · Analgesia $\cdot$ Infrared photo $\cdot$ Monitoring

\section{Paravertebral block basics}

Thoracic paravertebral block (TPVB) is a technique of injecting local anesthetic adjacent to the thoracic vertebra close to where the spinal nerves emerge from the intervertebral foramina. This results in ipsilateral somatic and sympathetic nerve blockade in multiple contiguous thoracic dermatomes above and below the site of injection [1, 2]. It is effective in treating acute and chronic pain of unilateral origin from the chest and abdomen [3-5].

TPVB is an old method of regional analgesia that was first described in the beginning of last century. In 1905 Hugo Sellheim from Leipzig described anatomical space lying alongside vertebral column. Following this discovery Sellheim and Lawen decided to inject small doses of local anesthetics into this space and to observe the effects [1].

This technique causes very good pain relief effect and also excellent pulmonary function preservation as well as great hemodynamic stability [6-8]. There is a short list of adverse effects and possible complications. Hypotension$4.6 \%$; Vascular puncture-3.8 \%; Pleural puncture$1.1 \%$ Pneumothorax $-0.5 \%$. Coagulation disorders are rather relative contraindications for this technique [9].

At the Department of General, Oncological, Metabolical and Thoracosurgery first paravertebral block was performed in 2000 for analgesia of multiple rib fractures. Since then we performed a lot of PVBs mostly for breast surgery and 
Table 1 Results from average infrared photo temperature reading

\begin{tabular}{llllll}
\hline $\begin{array}{l}\text { Marked } \\
\text { segment }\end{array}$ & $\begin{array}{l}\text { Time } \\
0\end{array}$ & $\begin{array}{l}\Delta \text { Time } 0 \\
\text { to }+20\end{array}$ & Time +20 & $\begin{array}{l}\Delta \text { Time } \\
+20 \text { to } \\
+30\end{array}$ & Time +30 \\
\hline seg Th2 & 33.1 & 1.3 & 34.4 & 1.1 & 35.5 \\
$\begin{array}{l}\text { seg } \\
\text { Th2-3 }\end{array}$ & 34.1 & 1.1 & 35.2 & 0.1 & 35.3 \\
seg & 33.3 & 1.2 & 34.5 & 0 & 34.5 \\
Th3-4 & & & & & \\
seg Th4 & 32.6 & 0.8 & 33.4 & 1.4 & 34.8 \\
seg Th5 & 33.2 & 0.7 & 33.9 & 0.4 & 34.3 \\
\hline
\end{tabular}

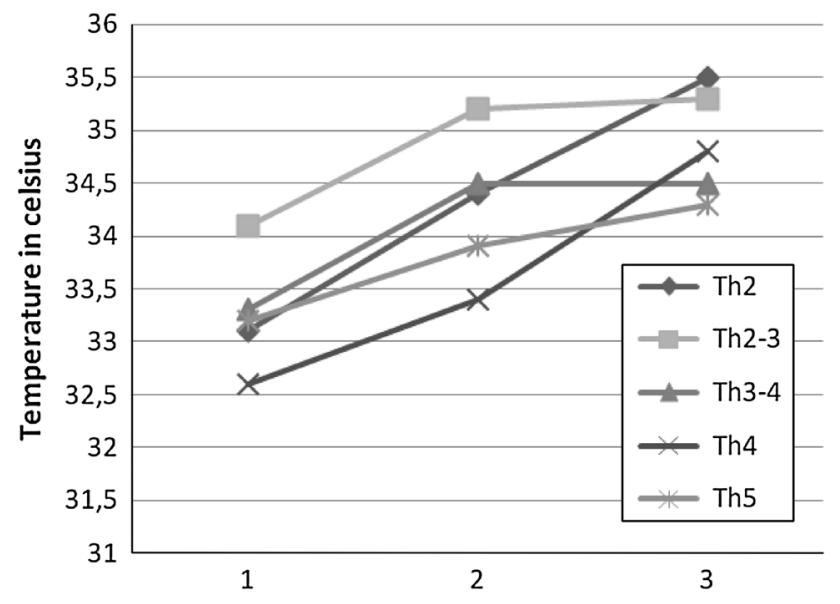

Fig. 1 Temperature changes in check points. 1-before blockade, 2-20 min after blockade, 3-30 min after blockade

thoracosurgery with very good analgesic effect and great preservation of pulmonary function.

\section{Case}

66 year old woman $(156 \mathrm{~cm}, 80 \mathrm{~kg}$, BMI 32) presented for elective mastectomy due to breast cancer. She suffered from severe COPD and also bullous emphysema. FVC 1.59 1; FEV1 0.55 1; FEV1 \%FVC 34.6. She was on home oxygen therapy. Chronic right heart failure, hypertension and obesity were the other problems.

The paravertebral block was performed using the multishot percutaneous technique at Th3, Th4, Th5 and Th6. We used $22 \mathrm{ml}$ of $0.75 \%$ ropivakaine with $0.2 \mathrm{mg}$ of fentanyl. For confirmation, of proper analgesia range, control of temperature changes, using infrared camera was performed. Then light general anesthesia with laryngeal mask (LMA) and sevoflurane was performed.

Infrared photo were made from around $0.5 \mathrm{~m}$ distance with FLIR i7 camera, with preservation of proper standards

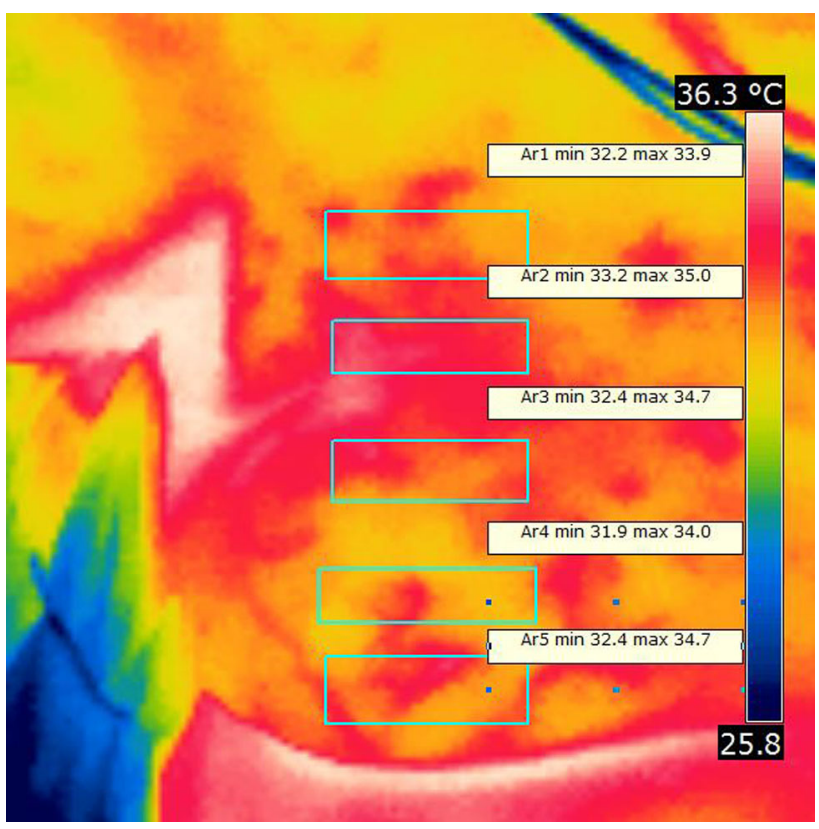

Fig. 2 Infrared photo made before paravertebral blockade

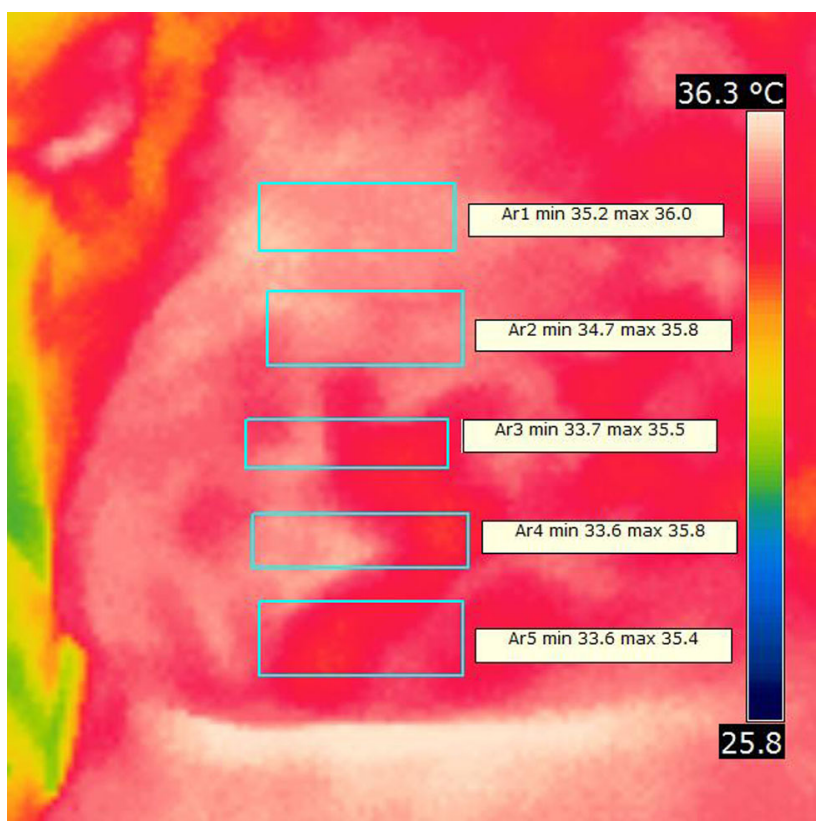

Fig. 3 Infrared photo made 30 min after paravertebral blockade

[10]. Patient was uncovered while performing the exam. First picture was made before performing of paravertebral blockade procedure. Paravertebral multi-shot procedure took $6 \mathrm{~min}$ to perform. First control photo was made $20 \mathrm{~min}$ after the blockade and next $10 \mathrm{~min}$ after. Temperature average was marked for chosen representative area for every segment needed to be anesthetized to perform planed 
surgery. For every marked area we observed rise in temperature reading from infrared camera photo, which was indirect confirmation of proper paravertebral blockade. Data shown in Table 1, Fig. 1.

Similar method of confirmation was previously used in S.P.S Cheema study of paravertebral analgesia. They have received confirmation of proper range of analgesia corresponding to ipsilateral temperature changes marked in infrared technique in six patients. Thus different level of paravertebral block was used in that study [11].

Infrared photo showed rise of temperature count in every marked region after $20 \mathrm{~min}$ from injection. Latter infrared temperature reading also showed further increase of marked temperature confirming sympathetic nervous system blockade and indirectly proper range of analgesia. Example infrared pictures are in Figs. 2 and 3.

The patient received very good intraoperative analgesia with high cardiovascular stability and very good respiratory function preservation.

There were no hemodynamic and pulmonary complications postoperatively.

\section{Conclusion}

Paravertebral block in combination with sedation creates excellent conditions for breast surgery procedures. Additional temperature changes monitoring performed with infrared camera may confirm proper range of analgesia needed to perform surgery. Great cardiovascular stability and very good pulmonary function preservation make this method excellent for high risk patients. Low complication rate is additional advantage. In our opinion this method is recommendable.

Ethical standards Described case report is complain with current law in Poland. Proper informed consent for anesthesia from patient was obtained.
Conflict of interest Not declared.

Open Access This article is distributed under the terms of the Creative Commons Attribution License which permits any use, distribution, and reproduction in any medium, provided the original author(s) and the source are credited.

\section{References}

1. Karmarkar MK. Thoracic paravertebral blockade. Anesthesiology. 2001;95:771-80.

2. Gilbert J, Hultman J. Thoracic paravertebral block: a method of pain control. Acta Anaesthesiol Scand. 1989;33:142-5. doi:10. 1111/j.1399-6576.1989.tb02877.x.

3. Karmakar MK, Chui PT, Joynt GM, Ho AM (2001) Thoracic paravertebral block for management of pain associated with multiple fractures ribs in patients with concomitant lumbar spinal trauma. Regional Anesthesia and Pain Medicine Mar/Apr; 26, doi:10.1053/rapm.2001.21086.

4. Lönnqvist P-A. Pre-emptive analgesia with thoracic paravertebral blockade? Br J Anaesth. 2005;95:6. doi:10.1093/bja/aei268.

5. Ferrandiz M, Aliaga L, Catala E, Villar-Landeira JM. Thoracic paravertebral block in chronic postoperative pain. Reg Anesth. 1994;19:221-2.

6. Wang JY. Post-thoracotomy epidural versus paravertebral analgesia. Br J Anaesth. 2000;84(2):289-90.

7. Richardson J, Sabanathan S, Shah R. Post-thoracotomy spirometric lung function: the effect of analgesia: a review. J Cardiovasc Surg. 1999;40:3.

8. Schnabel A, Reichl SU, Kranke P, Pogatzki-Zahn EM, Zahn PK. Efficacy and safety of paravertebral blocks in breast surgery: a meta-analysis of randomized controlled trials. $\mathrm{Br} \mathrm{J}$ Anaesth. 2010;105(6):842-52. doi:10.1093/bja/aeq265.

9. Wyatt SS, Price RA. Complications of paravertebral block. Br J Anaesth. 2000;84:3.

10. Ring EFJ. Quality control in infrared thermography. In: Ring EFJ, Phillips B, editors. Recent advances in medical thermology. New York: Plenum; 1984. p. 185-94.

11. Cheema SPS, Ilsley D, Richardson J, Sabanathan S. A thermographic study of paravertebral analgesia Anesthesia. 1995;50: $118-21$. 